\title{
NHÂN MỘT TRƯờnG HỢP SUY HÔ HẤP CẤP DO SA VAN HAI LÁ CẤP KHÔNG ĐÁP ƯNG VỚI ĐIỀU TRI THƯỜnG QUY ĐỰ̛̣C HỖ TRỢ V-V ECMO VÀ PHẪU THUẠTT THAY VAN CẤP
}

\begin{abstract}
Nguyê̂n Quang Thắng ${ }^{*}$, Nguyễn Đăng Tuân ${ }^{*}$, Lê Văn Bình ${ }^{*}$, Nguyễn Ngọc Quang ${ }^{*}$, Lê Thái Bảo*, Trần Trường Giang ${ }^{*}$, Nguyễn Công Hòa ${ }^{*}$, Nguyê̂n Sinh Hiền ${ }^{* *}$,Bùi Đúc Phü ${ }^{*}$
\end{abstract}

\section{TÓM TẮT}

Giới thiệu: Sa van hai lá (SVHL) cấp tính do đứt dây chằng van hai lá là nguyên nhân gây sốc tim cấp, suy hô hấp cấp gây đe dọa tính mạngnếu người bệnh không được cấp cứu và điều trị kịp thời và phù hợp. Các biện pháp điều trị kinh điển bao gồm hỗ trợ tình trạng suy hô hấp, tuần hoàn cấp giúp cứu nguy tính mạng với các biện pháp như: thở máy kiểm soát, và kiểm soát huyết động bằng thuốc, tuy nhiên khi tình trạng sốc và suy hô hấp không đáp ứng với các đều trị thường quy thì kỹ ECMO được coi là phương pháp điều trị cứu cánh, giúp duy trì tính mạng người bệnh để tiếp tục thực hiện các biện pháp

Tù̀ khóa: Sa van hai lá cấp, ECMO V-V cứu cánh suy hô hấp cấp.

\section{SUMMARY}

Acute mitral valve prolapse due to chordae tendinae rupture is the main etiology leading to acute cardiogenic shock and acute respiratory failure that is life threatening if it was not having any critical treatment timely and appropriately. All routine treatments include ventilation control, maintaining hemodynamic by vasopressors. However, if they were not working, ECMO (extracorporeal membrane oxygenation) is considered a salvage method to save enough time for applying others to save patient's life.

\section{I. ĐặT VẤN ĐỂ}

Sa van hai lá cấp tính là nguyên nhân hiếm gặp, có thể do hậu quả của nhồi máu cơ tim cấp gây thiếu máu vùng cầu cơ, gây hoại tử hoặc do nguyên nhân nhiễm khuẩn (viêm nội tâm mạc cấp hoặc bán câp) hoặc do nguyên nhân thoái hóa, hậu quả gây giảm cung lượng tim đột ngột do dòng phụt ngược từ thất trái lên nhĩ trái, gây tăng áp lực động mạch phổi, gây phù phổi cấp và suy hô hấp cấp nặng và có thể kèm theo cả suy tuần hoàn đi kèm. Trong một số trường hợp suy hô hấp nặng và suy tuần hoàn nặng không đáp ứng với các biện pháp điều trị thường quy như đảm bảo huyết động bằng dịch, thuốc vận mạch và biện pháp thở máy kiểm soát hoàn toàn với $\mathrm{FiO}_{2} 100 \%$, PEEP tối ưu, thì ECMO (V-V ECMO hoặc V-A ECMO được coi là biện pháp cứu cánh giúp duy trì tính mạng người bệnh và có thể tiến hành các biện pháp chẩn đoán và can thiệp tiếp theo. Từ năm 2017, khoa Hồi sức tích cực BV Đa khoa quốc tế Vinmec đã triển khai kỹ thuật ECMO cho các bệnh nhân suy hô hấp cấp và/hoặc suy tuần hoàn cấp không đáp ứng với các biện pháp điều trị thường quy và đã mang lại kết quả khả quan cho người bênh, chúng tôi xin giới thiệu ca lâm sàng điển hình suy hô hấp cấp nặng đã được cứu sống nhờ triển khai kỹ thuật ECMO.

\section{CA LÂM SÀNG}

Tiền sử: tăng huyết áp nhiều năm, điều trị thuốc amlordipine $5 \mathrm{mg} /$ ngày nhưng không đều,

\footnotetext{
* BV Vinmec Times City

** BV Tim Hà Nội

Ngườ chịu trách nhiệm khoa học: GS.TS.Bùi Đức Phú

Ngày nhận bài: 01/05/2019 - Ngày Cho Phép Đăng: 15/05/2019

Phản Biện Khoa họ: PGS.TS. Đặng Ngoc Hùng GS.TS. Lê Ngọc Thành
} 
đồng thời người bệnh có uống nhiều rượu nhưng không rõ số lượng.

Bệnh sư: Trước vào viện 02 ngày người bệnh (NB) xuất hiện mệt, ho khan, sốt nóng, sốt rét nhưng không cặp nhiệt độ, sau đó xuất hiện khó thở tăng dần, ngày cuối trước khi nhập việnNB xuất hiện mệt, khó thở hơn và đã đến khám tại phòng khám tư tại thành phố Hải Dương, được khám và chụp $\mathrm{X}$ quang (mò̀ thùy dưới phổi phải) và được chẩn đoán "viêm phổi/tăng huyết áp", và NBđược xử trí cefotaxin $1 \mathrm{~g}$ tiêm tĩnh mạch chậm, khí dung thuốc giãn phế quản tĩnh mạch, solumedrol 40mg tiêm tĩnh mạch, sau đó được chuyển lên khoa Cấp Cứu bệnh viên đa khoa Vinmec cùng ngày.

Người bệnh nhập khoa Cấp cứu trong tình trạng tỉnh (G15 điểm), thở 42 lần/phút, mạch 100 lần/phút, $\mathrm{SpO} 2$ 86\% (khí phòng), HA 176/90 $\mathrm{mmHg}$, nhiệt độ $37.4^{\circ} \mathrm{C}$. Khám phổi; rì rào phế nang (RRPN) phổi trái rõ, không có ral, RRPN phổi phải giảm ở đáy và có ran nổ rải rác. Khám tim; tần số tim 100 lần/phút, $\mathrm{T} 1$ và $\mathrm{T} 2$ đều rõ, tiếng thổi tâm thu (TTT) 3/6 mỏm tim. Khám bụng; gan lách không to, tĩnh mạch cổ không nổi và $\mathrm{NB}$ được làm các xét nghiệm máu và một số các thăm dò khác phục vụ cho chẩn đoán. Người bệnh được xử trí nằm đầu cao, thở oxy mask 10 $\mathrm{L} /$ phút sau đó tăng lên $15 \mathrm{~L} /$ phút và chuyển lên khoa Hồi sức tích cực (HSTC).

Người bệnh nhập khoa HSTC trong tình trạng; ý thức tỉnh (Glasgow 15 điểm), nói cấu ngắn, thở 26 lần/phút, HA 240/100 mmHg, $\mathrm{SpO}_{2}$ 92\% (oxy mặt nạ 15L/phút), mạch 100 lần/phút, phổi nghe ran ẩm 2 phổi, phổi phải nhiều. NB được xử tríthở máy không xâm nhập (BiPAP, IPAP $11 \mathrm{cmH} 2 \mathrm{O}$, EPAP $5 \mathrm{cmH} 2 \mathrm{O}$, FiO2 100\%), khoảng1 giờ sau tình trạng hô hấp diễn biến nặng dần không đáp ứng với thở máy không xâm nhập và sau đó đã được đặt ống nội khí quản, thở máy xâm nhập PEEP 10 - 14 cmH cm, $_{2} \mathrm{FiO}{ }_{2}$ 100\%, duy trì an thần và giãn cơ. Diễn biến sau 2 giờ thở máy xâm nhập mức tối ưu (PCV, IP $16 \mathrm{cmH}_{2} \mathrm{O}$, PEEP $14 \mathrm{cmH}_{2} \mathrm{O}, \mathrm{FiO}_{2}$ 100\%, f 28 lần/phút, an thần và giãn cơ), tình trạng suy hô hấp tiếp tục nặng lên và không đáp ứng với các biện pháp điều trị thường quy; M 138 ck/phút, HA 96/58 mmHg, $\mathrm{SpO} 286 \%$, trào nhiều dịch hồng qua ống NKQ, phổi ran ẩm 2 phế trường, bên phải nhiều hơn bên trái, duy trì huyết áp bằng noradrenalin truyền tĩnh mạch $\quad(0,2 \mu \mathrm{g} / \mathrm{kg} / \mathrm{phu} t), \quad$ dobutamin $(8 \mu g / k g / p h u ́ t)$,xét nghiệm khí máu pH 7,07, $\mathrm{PaCO}_{2}$ $56 \mathrm{mmHg}, \mathrm{PaO}_{2} 54 \mathrm{mmHg}, \mathrm{HCO}_{3}{ }^{-} 16,5 \mathrm{mmol} / \mathrm{L}$, lactat máu 5,96 mmol/L. Trước nguy cơ suy hô hấp nguy kịch đó, phương pháp ECMO V-V được nhanh chóng chỉ định nhằm cứu vãn tình trạng suy hô hấp cấp tính với các thông số hỗ trợ; $\mathrm{CO} 4$ L/phút, $\mathrm{FiO}_{2} 100 \%$, MV 4 L/phút, điều chỉnh lại thông số máy thở sau khi bắt đầu $\mathrm{ECMO} ; \mathrm{A} / \mathrm{C}$ $\mathrm{VCV}, \mathrm{Vt} 300 \mathrm{ml} /$ phút, f $8 \mathrm{ck} /$ phút, FiO2 60\%, PEEP $10 \mathrm{cmH}_{2} \mathrm{O}$. Diễn biến sau 2 giờ hỗ trợ bằng kỹ thuật $\mathrm{ECMO}$, tình trạng hô hấp và tuần hoàn người bệnh cải thiện hơn (bảng 1), tuy nhiên vẫn còn tình trạng thoát dịch nhiều qua ống nội khí.

quản, đặc biệt khi được hút đờm. Người bệnh sau đó được siêu âm tim phát hiện đứt dây chằng lá trước van hai lá, gây sa lá trước van hai lá và gây hở van hai lá nhiều, kèm hở chủ vừa, phân số tống máu EF $72 \%$, áp lực động mạch phổi50mmHg.

Sau 3 ngày điều trị tối ưu, tình trạng hô hấp và tuần hoàn không cải thiện hơn, thậm chí xu thế tồi đi, người bệnh được hội chẩn liên viện để xem xét chỉ định phẫu thuật cấp cứu nhằm sửa chữa các tổn thương cơ học và cuối cùng NB được được quyết định phẫu thuật thay van hai lá sinh học và thay van động mạch chủ sinh học vào ngày thứ 4 nhập ICU. Diễn biến sau phẫu thuật thay van 01 ngày tình trạng hô hấp 
tuần hoàn và hô hấp cải thiện rõ rệt (bảng 1), thuật ECMO V-V, và rút ống nội khí quản vào hết tình trạng phổi ướt và đã dừng được kỹ ngày 12 tại khoa HSTC.

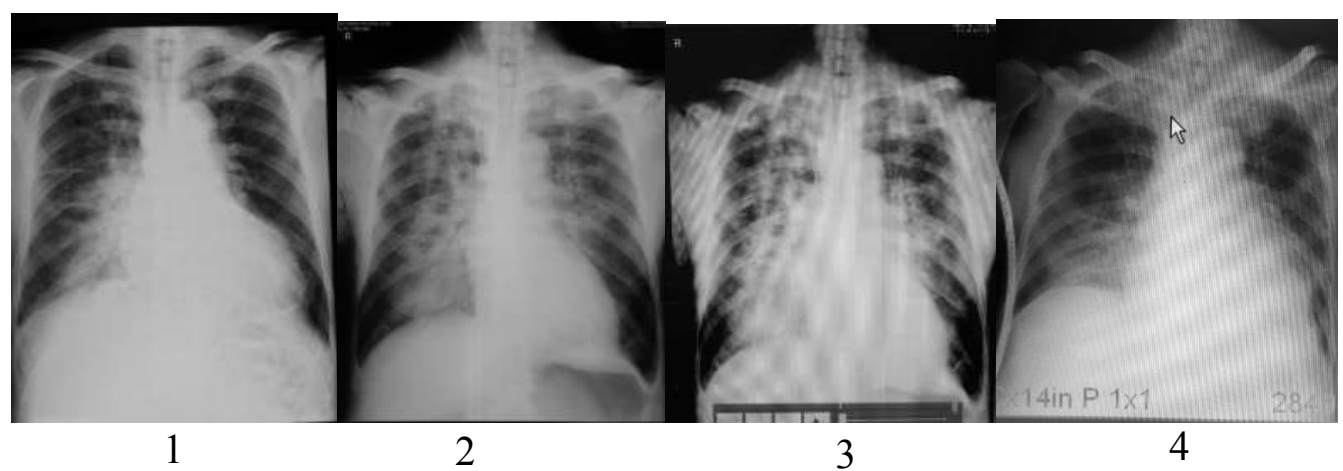

Hinh 2.1: Thay đổi hình ảnh X quang qua các thời điểm: 1: tại phòng khám Hải Dương;

2: khoa Cấp cúu sau khi hỗ trọ ECMO 2 giờ; 3: trước khi kết thúc ECMO và 4: thò̀i điểm chuyển viện

Diễn biến sau rút ống nội khí quản 24 giờ, NB đột ngột xuất hiện suy hô hấp trở lại, ống nội khí quản trào nhiều bọt hồng, $\mathrm{X}$ quang phổi mờ 2 phế trường, phổi phải mờ nhiều hơn, khí máu biểu hiện giảm thông khí phế nang và giảm oxy máu, siêu âm tim qua thành ngực và qua thực quản có hở chân nhiều van hai lá nhân tạo, sùi mặt sau van hai lá nhân tạo, EF \%, tăng ALĐMP nhiều, sốt 39 độ, marker nhiễm trùng tăng và cấy dịch hút phế quản mọc trực khuẩn mủ xanh đa kháng, cấy máu nhiều lần âm tính (bảng 2), không đáp ứng với liệu pháp điều trị kháng sinh trước đó bao gồm meropenem, vancomycin, cancidas. NB được điều trị kháng sinh theo phác đồ kháng sinh cho vi khuẩn đa kháng (phối hợp colistin tĩnh mạch và khí dung, piperacillin + tazobactam, vancomycin, cancidas và rifampicin), sau 1 tuần diều trị, tình trạng nhiễm khuẩn không cải thiện (vẫn sốt $39^{\circ} \mathrm{C}$, procalcitonin không giảm, suy thận không hồi phục, CRRT), NB được hội chẩn liên viện lần 2 và quyết định phẫu thuật lại lần 2 thay van 2 lá sinh học và van động mạch chủ sinh học, mục đích vừa loại bỏ ổ nhiễm khuẩn vừa nhằm mục đích lấy tổ chức sùi van hai lá cấy tìm vi khuẩn gây bệnh và lựa chọn kháng sinh nhạy cảm, tuy nhiên kết quả không mọc vi khuẩn.

Diễn biến sau phẫu thuật 01 tuần tình trạng nhiễm khuẩn cải thiện (bảng 2) mặc dù liệu trình kháng sinh trước đó không thay đổi, suy hô hấp cải thiện và người bệnh đã bỏ được máy thở và tự thở qua mở khí quản vào ngày thứ 19 và được chuyển viện khác để chăm sóc và phục hồi chức năng vào ngày điều trị thứ 30 . Kết quả người bệnh ra viện sau 2 tuần và hòa nhập cuộc sống bình thường.

Bảng 2.1: Thay đổi các thông số hô hấp và tuần hoàn tại các thời điểm nhập khoa cấp cúu, sau hồ trợ ECMO 6 giò̀, trước khi kết thúc ECMO

\begin{tabular}{|l|c|c|c|c|}
\hline \multicolumn{1}{|c|}{ Các thông số } & $\begin{array}{c}\text { Nhập khoa } \\
\text { Cấp cứu }\end{array}$ & Trước ECMO & ECMO 6 giờ & $\begin{array}{c}\text { Trước kết thúc } \\
\text { ECMO }\end{array}$ \\
\hline Mạch (lần/phút) & 100 & 115 & 104 & 82 \\
\hline Tần số thở (lần/phút) & 42 & 30 & 8 & 12 \\
\hline HATĐ/HATT (mmHg) & $176 / 90$ & $96 / 58$ & $107 / 52$ & $145 / 72$ \\
\hline
\end{tabular}




\begin{tabular}{|l|c|c|c|c|}
\hline HATB $(\mathrm{mmHg})$ & 119 & 71 & 70 & 96 \\
\hline Noradrenalin $(\mu \mathrm{g} / \mathrm{kg} / \mathrm{phút})$ & Không dùng & 0,1 & 0 & 0 \\
\hline Dobutamin $(\mu \mathrm{g} / \mathrm{kg} / \mathrm{phút})$ & Không dùng & 5 & 0 & 10 \\
\hline $\mathrm{PaO}_{2} / \mathrm{FiO}_{2}$ & 145 & 54 & & 300 \\
\hline $\mathrm{PaO}_{2}(\mathrm{mmHg})$ & 58 & 54 & 195 & 90 \\
\hline $\begin{array}{l}\mathrm{FiO}_{2}(\%) \\
(\mathrm{má} \text { thở/ECMO) }\end{array}$ & 40 & 100 & $60 / 100$ & $40 / 21$ \\
\hline $\mathrm{pH}$ & 7,48 & 7,07 & 7,34 & 7,50 \\
\hline $\mathrm{PaCO}(\mathrm{mmHg})$ & 25.6 & 56 & 35,7 & 30 \\
\hline $\mathrm{HCO}_{3}{ }^{-}(\mathrm{mmol} / \mathrm{L})$ & 19,2 & 16,5 & 19,4 & 24,4 \\
\hline Lactate $(\mathrm{mmol} / \mathrm{L})$ & 1,43 & 5,96 & 4,49 & 1,58 \\
\hline $\begin{array}{l}\text { Mode } \\
\text { Vt/IP/f/PEEP }\end{array}$ & Tự thở & A/C- & A/C-VCV & A/C-VCV \\
\hline APACHE II (điểm) & & VCV360/24/14 & $300 / 6 / 10$ & $500 / 14 / 8$ \\
\hline SOFA (điểm) & 25 & 28 & & 6 \\
\hline
\end{tabular}

Bảng 2.2: Diễn biến lâm sàng, cận lâm sàng thời điểm sau phẫu thuật thay van lần 1 một ngày, truớc đặt lại ống $N K Q$ và thời điểm sau thay van lần 2 một tuần và lúc chuyển viện

\begin{tabular}{|c|c|c|c|c|}
\hline Các thông số & $\begin{array}{l}\text { Sau phẫu thuật } \\
\text { thay van tim } \\
\text { lân } 1 \text { - } 01 \text { ngày }\end{array}$ & $\begin{array}{c}\text { Trước đặt lại } \\
\text { NKQ }\end{array}$ & $\begin{array}{l}\text { Trước phẫu thuật } \\
\text { thay van tim } \\
\text { lần } 2 \text { - một tuần }\end{array}$ & $\begin{array}{l}\text { Thò̀i điểm } \\
\text { chuyển viện }\end{array}$ \\
\hline Mạch (lần/phút) & 82 & 100 & 100 & 85 \\
\hline HATĐ/HATT (mmHg) & $145 / 72$ & $120 / 70$ & $100 / 60$ & $127 / 85$ \\
\hline HATB (mmHg) & 96 & 86 & 73 & 99 \\
\hline Noradrenalin ( $\mu \mathrm{g} / \mathrm{kg} / \mathrm{phút})$ & 0 & 0 & 0 & 0 \\
\hline Dobutamin $(\mu \mathrm{g} / \mathrm{kg} /$ phút $)$ & 10 & 7 & 3 & 0 \\
\hline $\mathrm{PaO}_{2} / \mathrm{FiO}_{2}$ & 30 & 203 & 234 & 483 \\
\hline $\mathrm{PaO}_{2}(\mathrm{mmHg})$ & 93 & 122 & 117 & 145 \\
\hline $\begin{array}{l}\mathrm{FiO}_{2}(\%) \\
\text { (máy thở/ECMO) }\end{array}$ & $40 / 21$ & 60 & 50 & 30 \\
\hline $\mathrm{pH}$ & 7,50 & 7,41 & 7,37 & 7,45 \\
\hline $\mathrm{PaCO}_{2}(\mathrm{mmHg})$ & 30 & 30,5 & 46 & 35,6 \\
\hline $\mathrm{HCO}_{3}^{-}(\mathrm{mmol} / \mathrm{L})$ & 24,4 & 19,7 & 27,3 & 24,8 \\
\hline Lactate $(\mathrm{mmol} / \mathrm{L})$ & 1,58 & 4,15 & 0,6 & 0,62 \\
\hline Nhiệt độ (độ C) & & 38,2 & 38,5 & 37 \\
\hline
\end{tabular}




\begin{tabular}{|l|c|c|c|c|}
\hline $\begin{array}{l}\text { Mode } \\
\text { Vt/IP/f/PEEP }\end{array}$ & $\begin{array}{c}\mathrm{A} / \mathrm{C}-\mathrm{VCV} \\
500 / 14 / 8\end{array}$ & $\begin{array}{c}\text { không xâm } \\
\text { nhập }\end{array}$ & $\begin{array}{c}\mathrm{A} / \mathrm{C}-\mathrm{VCV} \\
500 / 12 / 5\end{array}$ & Tự thở \\
\hline Bạch cầu $(\mathrm{G} / \mathrm{L})$ & 20,3 & 12,7 & 9,4 & 7 \\
\hline Procalcitonin $(\mathrm{ng} / \mathrm{mL})$ & 3,05 & 2,02 & 2,04 & 1,01 \\
\hline SOFA (điểm) & 7 & 8 & 7 & 4 \\
\hline Ure (mmol/L) & 17,6 & 12,2 & 10,3 & 10 \\
\hline Creatinin $(\mu \mathrm{mol} / \mathrm{L})$ & 218 & 166 & 147 & 266 \\
\hline Nước tiểu $(\mathrm{ml} / \mathrm{giờ})$ & 0 & 0 & 0 & 0 \\
\hline Vi khuẩn $($ dịch phế quản) & Mủ xanh & Mủ xanh & Mủ xanh & Âm tính \\
\hline
\end{tabular}

\section{BÀN LUẬn}

\subsection{ECMO có phải là biện hỗ trọ’ cứu} cánh trong các trường hợp suy hô hấp cấp không đáp ứng với các biện pháp điều trị thường quy?

Người bệnh nhập viện trong tình trạng suy hô hấp trên nền có ho, sốt và khó thở trước đó, vì vậy với tiếp cận và chẩn đoán ban đầu của bác sỹ tại khoa cấp cứu đã hướng tới căn nguyên suy hô hấp do viêm phổi. Tuy nhiên sau đó tình trạng suy hô hấp tiến triển khá nhanh và nặng nề kèm theo các dấu hiệu khá điển hình của phù phổi cấp huyết động, căn nguyên phù phổi cấp có thể do hở van hai lá do sa van hai lá, cơn tăng huyết áp $(240 / 100 \mathrm{mmHg})$ có thể hậu quả của suy hô hấp và là nguyên nhân làm tăng tổn thương sa van hai lá và hậu quả cuối cùng gây suy hô hấp nặng nề (giảm oxy máu nặng, giảm thông khí phế nang, toan hô hấp cấp - bảng 1), không đáp ứng với các biện pháp điều trị thường quy bao gồm các biện pháp tối ưu huyết động và tối ưu thở máy (bảng 1). Nếu không có các biện pháp điều trị khác tối ưu hơn, đột phá hơn thì kết cục tử vong của người bệnh chỉ là vấn đề thời gian, và ECMO V-V đã trở thành biện pháp cứu cánh. Bản chất của $\mathrm{V}-\mathrm{V}$ ECMO là biện pháp trao đổi khí ngoài cơ thể, ở đây máu tĩnh mạch nghèo oxy, dư thừa $\mathrm{CO}_{2}$ được đưa tới một màng trao đổi, tại đây máu được làm giàu oxy và loại bỏ $\mathrm{CO}_{2}$ sau đó đi vào tim phải lên phổi và vào vòng đại tuần hoàn để đi nuôi cơ thể, và kết quả đã sửa chữa được tình trạng giảm oxy máu, tăng $\mathrm{CO}_{2}$, hết toan hô hấp (bảng 1)[ㄹ],[ㅌ]].

Mặt khác một câu hỏi khác cũngđược đặt ra là "nên chỉ định V-V ECMO hay V-A ECMO cho trường hơp này?"

Về cơ chế V-A ECMO có vẻ logic hơn vì $\mathrm{NB}$ có cả suy tuần hoàn do giảm cung lượng tim và suy hô hấp cấp do ngập lụt các phế nang cấp tính, tuy nhiên do người bệnh có hở van động mạch chủ vừa đi kèm (mạn tính) hơn nữa $\mathrm{HA}$ trung bình người bệnh đã duy trì được mức $>65$ mmHg với liều vận mạch không cao (bảng 1), mặt khác $\mathrm{V}-\mathrm{V}$ ECMO ít biến chứng và dễ triển khai một cách nhanh chóng và kịp thời hơn[5] , ngoài ra nếu V-V ECMO thất bại, chúng ta vẫn có phương án dự phòng chuyển sang phương thức hỗ trợ $\mathrm{V}-\mathrm{AV}$ ECMO nhằm mục tiêu hỗ trợ cả hô hấp và tuần hoàn.

\section{Vai trò của bóng đối xung IABP?}

Bản chất bóng đối xung hỗ trợ tuần hoàn là chủ yếu thông qua giảm hậu gánh, cải thiện cung lượng tim (khoảng $0,5 \mathrm{~L} /$ phút), trường hợp người 
bệnh trên có hở chủ vừa nên sẽ hỗ trợ giảm được hậu gánh đánh kể, giúp cải thiện hô hấp[1]],[2] tuy nhiên nếu suy hô hấp và/hoặc suy tuần hoàn tiếp tục tiến triển nặng hơn thì ECMO vẫn là biện pháp cứu cánh[2]].

\subsection{Chỉ định phẫu thuật thay van trong} điều kiện cấp cứu có phải là một lựa chọn phù hợp?

Người bệnh đã được điều trị tối ưu trong vòng 2 ngày với hỗ trợ $\mathrm{V}-\mathrm{V}$ ECMO (bảng 2), tình trạng hô hấp không cải thiện, phổi rất nhiều dịch hồng (phổi phải nhiều hơn), vì bản chất là hở hai lá cấp, có tính chất cơ học, nếu không sửa chữa sẽ khó cải thiện tình hình, hơn nữa nếu kéo dài thời gian điều trị cũng như thời gian hỗ trợ kỹ thuật sẽ làm tăng nguy cơ tử vong do nhiễm khuẩn bệnh viện và biến chứng suy đa tạng. Các tác giả ngoài nước cũng thống nhất nên phẫu thuật sớm sửa chữa rối loạn huyết động do nguyên nhân cơ học đối với các trường hợp hở van hai lá cấp do sa van hai lá cấp [2]],[4]],[]],[]].

\subsection{Thách thức điều trị nhiễm khuẩn đa} kháng và quyết định phẫu thuật thay van lần thứ 2?

Thủ phạm gây hở chân van hai lá nhân tạo khả năng nhiều là do viêm nội tâm mạc cấp (hình ảnh sùi trên siêu âm thực quản, sốt và procalcitonin tăng), kèm theo NB đang có nhiễm khuẩn phổi (cấy nhiều lần mọc trực khuẩn mủ xanh đa kháng), thất bại với phác đồ điều trị trước đó (meropenem, colistin truyền tĩnh mạch, vancomycin, kháng nấm cancidas). Vấn đề đặt ra nếu không phẫu không thể loại bỏ được ổ nhiễm khuẩn vì phác đồ kháng sinh sử dụng không hiệu quả và là một trong nguyên nhân thất bại, tuy nhiên nếu phẫu thuật khả năng thất bại rất cao (xuất hiện sùi lại với các van nhân tạo) [3] ]. Tuy nhiên người bệnh vẫn được quyết định thay van nhân tạo lần 2 , và diễn biến sau đó tình trạng nhiễm khuẩn cải thiện với phác đồ kháng sinh giữ nguyên (colistin khí dung kết hợp truyền tĩnh mạch, piperacillin + tazobactam, vancomycin, cancidas và rifampicin).

\section{KẾT LUẬN}

Bệnh nhân suy hô hấp cấp đe dọa tính màng ở người bệnh phù phổi cấp huyết động do sa van hai lá cấp do đứt dây chằng van hai lá cấp, kèm hở chủ vừa không đáp ứng với các biện pháp điều trị thường quy thì $\mathrm{V}-\mathrm{V}$ ECMO là biện pháp điều trị cứu cánh, giúp duy trì tính mạng, giúp có đủ thời gian làm các xét nghiệm chẩn đoán và các biện pháp điều trị đặc hiệu tiếp theo giúp cứu sống người bệnh.

\section{TÀI LIẸU THAM KHẢO}

1. Dekker AL, Reesink KD, van der Veen FH, van Ommen GV, Geskes GG, Soemers AC, Maessen JG (2003) Intra-aortic balloon pumping in acute mitral regurgitation reduces aortic impedance and regurgitant fraction. Shock (Augusta, Ga) 19:334-338

2. Kim TS, Na C-Y, Baek JH, Kim J-H, Oh S-S (2011) Preoperative Extracorporeal Membrane Oxygenation for Severe Ischemic Mitral Regurgitation - 2 case reports. The Korean Journal of Thoracic and Cardiovascular Surgery 44:236-239

3. Maciejewski M, Piestrzeniewicz $\mathrm{K}$, Bielecka-Dąbrowa A, Piechowiak M, Jaszewski $R$ (2011) Redo surgery risk in patients with cardiac prosthetic valve dysfunction. Archives of Medical Science : AMS 7:271-277

4. Russo A, Suri RM, Grigioni F, Roger VL, Oh JK, Mahoney DW, Schaff HV, EnriquezSarano M (2008) Clinical outcome after surgical correction of mitral regurgitation due to papillary muscle rupture. Circulation 118:1528-1534. 
5. Staudacher D, Bode C, Wengenmayer $T$ (2015) Severe Mitral Regurgitation Requiring ECMO Therapy Treated by Interventional Valve Reconstruction Using the MitraClip

6. Tavakoli R, Weber A, Brunner-La Rocca H, Bettex D, Vogt P, Pretre R, Jenni R, Turina M (2002) Results of surgery for irreversible moderate to severe mitral valve regurgitation secondary to myocardial infarction. European journal of cardio-thoracic surgery : official journal of the European Association for
Cardio-thoracic Surgery 21:818-824.

7. Yamanishi H, Izumoto H, Kitahara H, Kamata J, Tasai K, Kawazoe K (1998) Clinical experiences of surgical repair for mitral regurgitation secondary to papillary muscle rupture complicating acute myocardial infarction. Annals of thoracic and cardiovascular surgery : official journal of the Association of Thoracic and Cardiovascular Surgeons of Asia 4:83-86. 